Total Word Count (including abstract, text, references, and tables): 5,480

\title{
The prevalence of cognitive impairment among people attending a homeless service in Far North Queensland with a majority Aboriginal and/or Torres Strait Islander people
}

Objective: To established the point prevalence of cognitive impairment among a representative group of homeless people in Cairns. This included a large number of Aboriginal and/or Torres Strait Islander people.

Method: This research was conducted among an opportunistic sample of participants residing in a homeless shelter. An interview administered cross-sectional survey was conducted with 60 participants over 12 weeks. The Kimberly Indigenous Cognitive Assessment (KICA-Cog) and a clinical diagnosis by a psychiatrist (using DSM-V criteria) were used to establish cognitive impairment. The 36-item version of the World Health Organisation Disability Assessment Survey 2.0 (WHODAS 2.0) was employed to ascertain limitations in daily living activities.

Results: Seventy-five percent of participants were Aboriginal and/or Torres Strait Islander people. Thirty-five percent of the sample had a cognitive impairment based on the KICA-cog while over 70\% of the sample had a cognitive impairment based on clinical criteria. Being screened for dementia or global cognitive impairment according to the KICA-Cog was significantly correlated with having greater difficulty across the following WHODAS domains: Understanding or Communicating, SelfCare, and Life Activities.

Conclusions: Many people who are homeless have a cognitive impairment and this impairment impacts their ability to participate in society. A shift in practice is necessary to support homeless populations with a high proportion of Aboriginal and/or Torres Strait Islander people. It is important that culturally appropriate methods - focusing on cognitive health - are employed to support Aboriginal and/or Torres Strait Islander people who are homeless.

Key Words: Aboriginal and/or Torres Strait Islander, Activities of Daily Living, Cognitive Impairment, Homelessness

\section{What is already known on this topic:}

Homeless populations are a hard to reach group which makes it difficult to ascertain the level and extent of cognitive impairment they experience.

A growing body of research is beginning to establish that a high proportion of homeless populations experience cognitive impairment.

A paucity of research has investigated the level of cognitive impairment among homeless people in Australia which include a high proportion of Aboriginal and/or Torres Strait Islander people.

\section{What this paper adds:}

Findings from this study affirm that a high proportion of people - including a considerable proportion of Aboriginal and/or Torres Strait Islander people - attending a homeless shelter in Far North Queensland are experiencing cognitive impairment.

Activities of daily living are compromised and for participants, participating in society and getting along with other people are domains which are most difficult. 
It is imperative that homeless policy and service development is informed by evidence regarding the complex needs of homeless people in general; and, built on Aboriginal and/or Torres Strait Islander principles.

\section{Introduction}

There is limited evidence about the prevalence of cognitive impairment among homeless populations. This is especially the case for those which include a high proportion of Aboriginal and/or Torres Strait Islander people (Avery, 2016). This lack of understanding is partially due to the absence of culturally appropriate assessment tools (Hux, Schneider, \& Bennett, 2009; O'Brien, Townsend, Cullen, White, \& Webster, 2014; Cullen, Townsend, White, \& O’Brien, 2014; Dudley, 2013; Dudley, Wilson, \& Barker-Collo, 2014) and the social marginalisation of Aboriginal and/or Torres Strait Islander people (Productivity Commission [PC], 2011). Research has begun to explore the prevalence of cognitive impairment amongst homeless populations and the association between cognitive impairment and homelessness (Stergiopoulos et al., 2015; Solliday-McRoy, Campbell, Melchert, Young, \& Cisler, 2004; Spence, Stevens, \& Parks, 2004; Burra, Stergiopoulos, \& Rourke, 2009). While research in the area is limited (Stergiopoulos et al., 2015), findings generally suggest that homelessness is associated with cognitive impairment (Burra et al., 2009; Spence, Stevens, \& Parks, 2004). However it is also important to consider that bi-directionality of causation is likely and factors outside homelessness for example, having "poor brain health" during childhood (Caspi et al., 2016) - may also contribute.

Three systematic reviews have synthesised findings from studies investigating the extent of cognitive impairment among homeless populations (Spence et al., 2004; Burra et al., 2009; Fazel, Khosla, Doll, \& Geddes, 2008). Spence, Stevens, and Parks (2004) reviewed 18 studies concerning cognitive impairment and homelessness and found an association between homelessness and global cognitive impairment. Burra, Stergiopoulos, and Rourke (2009) reviewed 22 articles published between 1970 and 2007 assessing cognitive impairment of homeless adults. Findings included that $4-7$ percent of homeless persons experience global cognitive deficits and deficits also exist across memory, cognitive 
processing and executive function. The authors concluded that cognitive deficit is an issue amongst the population that requires targeted service delivery.

Cognitive impairment within Australian Aboriginal and/or Torres Strait Islander populations has received limited attention (Biddle, Yap, \& Gray, 2013; Glasson, Sullivan, Hussain \& Bittles, 2005). Specifically, there is a dearth of accurate prevalence, demographic or qualitative data that identifies the experiences and needs of Aboriginal and/or Torres Strait Islander homeless people who have cognitive impairment (Avery, 2016). This information is needed to inform policy and service development and to ensure that Aboriginal and/or Torres Strait Islander people's perceptions and needs drive the development of services and supports. Many homelessness interventions focus on housing while not considering underlying conditions which may contribute to homelessness (Caton, Wilkins \& Anderson, 2007) and there is a paucity of homelessness services which address the unique cognitive needs of Indigenous people globally (Roy, Noormohamed, Henderson, \& Thurston, 2015; Thurston, Oelke, \& Turner 2013). Consequently, approaches to policy and service development and provision among Aboriginal and/or Torres Strait Islander homeless populations must be underpinned by accurate data as to the level and nature of needs.

By focusing on the prevalence of cognitive impairment among a group which includes a high proportion of Aboriginal and/or Torres Strait Islander people, there is potential to perpetuate the deficit perspective of Aboriginal and/or Torres Strait Islander people (Fforde, Bamblett, Lovett, Gorringe \& Fogarty, 2013). At the same time such research provides insight into the cognitive health issues experienced by the group and may inform acceptable, and culturally appropriate intervention and support programs. Hunter argues that "Denying or minimising disorder or disease in a crosscultural context is disarmingly easy and dangerous. There is no simple solution, one strives for openness to the cultural dimension of human existence while retaining clinical vigilance" (Hunter, 1993, p. 8). As a result, the authors argue that it is important to undertake research to ascertain the prevalence of cognitive impairment among homeless populations, especially those which include a high proportion of Aboriginal and/or Torres Strait Islander people. 
The current study aimed to establish the point prevalence of cognitive impairment among a representative group of the homeless people in Cairns and the impact of impairment on activities of daily living. This included a large number of Aboriginal and/or Torres Strait Islander people. One of the outcomes of the current study was to assist marginalised groups to engage with the National Disability Insurance Scheme (Author's Own, 2017a,b). The project methodology needed to consider a strata of barriers in sampling the identified population and whether it might be possible to generalise some of the results. Tourangeau (2016) distinguishes populations that are:

1. hard to sample,

2. whose members who are hard to identify,

3. those that are hard to find or contact,

4. those whose members are hard to persuade to take part, and

5. those whose members are willing to take part but nonetheless hard to interview.

Mobile or "elusive" populations present particular difficulties for sample designers. These are populations, such as mobile Aboriginal and/or Torres Strait Islander populations in Far North Queensland or homeless groups that are not easily linked to any one place. Here, the best sampling strategy often involves sampling places where the members of the elusive populations are likely to be found. Kalton (2009) describes this approach as "location sampling" and includes sampling homeless shelters (Ardilly \& Le Blanc, 2001)

\section{Method}

\section{Context}

Cairns is a city located in Far North Queensland, approximately 1,700 kilometers from Brisbane (Queensland Council of Social Service [QCOSS], 2016). The city has a population of approximately 160,000 people, and the median age is 36.5 , which is lower than the Australian average (Australia Bureau of Statistics [ABS], 2015). Cairns has a relatively high proportion of Aboriginal and/or Torres 
Strait Islander people at 9.3 percent (QCOSS, 2016), compared to 3.6 percent for the State of Queensland (ABS, 2015). The unemployment rate in Cairns is 7.4 percent and this is higher than the unemployment rate within the state of Queensland which is 5.9 percent (Queensland Council of Social Service [QCOSS], 2016). The largest industry in Cairns is Health Care and Social Assistance employing over 9,187 people, the second largest industry Retail Trade employs 8,779 people and the third largest industry Accommodation and Food Services employs 7,632 people (Cairns Regional Council [CRC], 2017).

It is difficult to ascertain a definitive number of homeless people in Cairns. Recent data has indicated that there are approximately 3,827 people who are homeless or at risk of homelessness (QCOSS, 2016). In 2011, approximately 246 of the 1,391 homeless people at the time were Aboriginal and/or Torres Strait Islander people (QCOSS, 2011). The difference between 2016 and 2011 QCOSS estimates are likely due to the difficulty definitively ascertaining an estimate of such a transient population. Given the difficulty in obtaining a definitive number of homeless people in Cairns, it is quite possible that the number of homeless people is far greater. To date there are at least 21 organisations providing advocacy and support to homeless people in Cairns (QCOSS, 2016). Despite significant resources being devoted to homelessness, it remains an area of significant concern for service providers, Government and Aboriginal and/or Torres Strait Islander community members.

\section{Participants}

This research was conducted among difficult to reach sample of participants residing in a homeless shelter. Participants included individuals using the shelter on any night during a 12 week assessment phase throughout September to November 2015. All people presenting to the service during this period were offered an opportunity to participate.

Throughout the 12 week period, 136 persons utilised the service, of who 60 consented to participate. Table 1 below provides detailed participant information and information for all service users. In terms of ethnicity $75 \%$ were Aboriginal and/or Torres Strait Islander, $67.7 \%$ were male and the highest proportion of persons were between the ages of 30-49 years old. When compared to the service user 
population during the time period, a higher proportion of the sample were Aboriginal and/or Torres Strait Islander, and the difference between groups was significant (using Fisher's Exact Test). In terms of homelessness, 48 participants indicated being homeless within the last month and 58 participants indicated being homeless for over a week over the last year. Additionally, 20 participants indicated living at more than one location during the last month and 41 participants indicated living at more than one location for over a week during the last year. Finally, in terms of employment, $98.3 \%$ persons were unemployed and $58.3 \%$ of persons indicated that they were unemployed due to mental health issues. In terms of support, 38.3\% indicated receiving a disability support pension.

[Insert Table 1 Here]

\section{Procedure}

Prior to undertaking this research, a Cultural Advisor spent 12 weeks at the shelter developing rapport and trust with shelter occupants. Over time the Cultural Advisor and the Research Team were able to discuss the project and its methodology with the occupants and engaged in a range of cultural ceremonies to allow the team to commence the project. Potential participants were then approached, briefed about the project and asked if they would be willing to be assessed. The essential component in developing cross-cultural communication skills is contact. Every contact is a lesson (Hunter, 1993). Participants were offered a culturally safe and appropriate clinical cognitive assessment. All participants were informed they could select out of the assessment at any time without this impacting on their relationship with the Shelter. Participants were also advised they would not be identified by name in any project reports. Where participants were found to have a health condition requiring immediate treatment this was addressed by the medical specialists within the Project Team in collaboration with the Shelter medical staff. Ethics approval was provided by Far North Queensland Health Research Ethics Committee.

\section{Measures}


An interview protocol was utilised. The initial section gathered background information. After, the protocol included separate measures to ascertain (i) cognitive impairment, and (ii) limitations in activities of daily living.

\section{Background information}

Initially background information was gathered as a part of the interview protocol. Self-reported data included: gender, age (date of birth), Aboriginal and/or Torres Strait Islander identification, residence history (currently, and during the year), education history, employment history, and receipt of pension or benefits.

\section{Kimberly Indigenous Cognitive Assessment}

The Kimberly Indigenous Cognitive Assessment (KICA; LoGiudice et al., 2006) was developed as a validated screening tool for dementia among older Aboriginal and/or Torres Strait Islander people residing in remote regions of Australia (LoGiudice et al., 2006; Smith et al., 2009). The tool is comprised of the following sections: medical history, smoking and alcohol history, KICA-Cog for cognitive assessment, and the KICA-Dep for depression assessment. The tool also includes a family report section where family members can provide opinions concerning a participants': medical history, drug and alcohol use, cognitive assessment, behaviour, and their ability to complete daily tasks.

As a part of this research the KICA-Cog (LoGiudice et al., 2006) was employed to screen for cognitive impairment. The KICA-Cog (LoGiudice et al., 2006) includes sixteen questions which fall under the domains: orientation, recognition and naming, registration, verbal comprehension, verbal fluency, recall, visual naming, frontal/executive function, free recall, cued recall and praxis. The scale is scored out of 39 where a score equal to or below 33 is indicative of a cognitive impairment possibly dementia.

Previous studies have established the KICA-Cog as a valid and reliable measure. Criterion-related validity has been established for the KICA-Cog by LoGiuidice et al. (2006) and Smith et al. (2009). 
Initially, LoGiudice et al. (2006) evaluated the psychometric properties of the KICA-Cog among 70 participants from the Kimberley region. Criterion-related validity was measured by comparing KICACog scores with clinician diagnosis for cognitive impairment based on DSM-IV (American Psychiatric Association [APA], 2013) and ICD-10 (World Health Organization [WHO], 1993) criteria. The KICA-Cog produced high levels of sensitivity and specificity, indicative of the measure being valid. Furthermore, Smith et al. (2009) re-evaluated the psychometric properties of the KICACog among two samples (a sample from the Northern Territory and a sample from the Kimberley). Criterion-related validiy was also established by comparing KICA-Cog scores with clincian diagnosis for cognitive impairment based on DSM-IV (APA, 2013) and ICD-10 (WHO,1993) criteria. Similar to LoGiudice et al. (2006) high levels of sensitivity and specificity were apparent across both samples, leading the authors to conclude that the measure is valid. These studies have also established the KICA-Cog as a reliable measure, producing alpha scores of .81 (Smith et al., 2009), .91 (Smith et al., 2009), and .88 (LoGiudice et al., 2006). For the current study, the KICA-Cog produced an internal consistency of $\mathrm{a}=.725$ indicative of the measure being reliable.

\section{Clinical Diagnosis of Cognitive Impairment}

A psychiatrist experienced in the assessment of people with cognitive impairment including Aboriginal and/or Torres Strait Islander people conducted a standard clinical assessment of all participants. Diagnosis was according to DSM-V (APA, 2013) criteria for cognitive disorders. Diagnosis was informed by the approaches of Smith et al. (2009) and LoGiudice et al. (2006). Specifically, clinical evaluation involved determination of past and present history, medications, informant report, and behavioural, psychological and cognitive assessment. This assessment was independently evaluated by two clinical nurse consultants to reach a consensus diagnosis using DSMV diagnostic criteria (APA, 2013).

\section{Activities in Daily Living}

The 36-Item World Health Organisation Disability Assessment Schedule (WHODAS) 2.0 (World Health Organisation [WHO], 2017) was used to measure difficulties in activities of daily living. The 
WHODAS 2.0 is grounded in the International Classification of Functioning, Disability and Health and is used to establish general health and disability (WHO, 2017). Specifically, the WHODAS 2.0 integrates an individual's level of functioning in major life domains and directly corresponds with ICF's "activity and participation" dimensions. Responses options for each question are on a five point likert scale which include: 0 'no difficulty', 1 'mild difficulty', 2 'moderate difficulty', 3 'severe difficulty', and 4 'extreme difficulty or cannot do'.

The WHODAS 2.0 includes six domains of functioning including:

- Cognition - understanding \& communicating

- Mobility- moving \& getting around

- Self-care- hygiene, dressing, eating \& staying alone

- Getting along-interacting with other people

- Life activities- domestic responsibilities, leisure, work \& school

- Participation-joining in community activities

Various studies have tested the psychometric properties of the WHODAS 2.0. Federici, Bracalenti, Meloni, and Luciano (2017) conducted a systematic review to identify applications of the WHODAS 2.0 and identify research where the psychometric properties of the tool had been tested. Their review synthesised research utilising the tool between 1999 and 2015 and identified 811 studies from 94 countries. They identified 28 studies where the internal consistency of the WHODAS 2.0 was measured. Three of the identified studies measured the internal consistency for each of the six domains of the 36-item WHODAS 2.0, amongst people with cognitive impairment (Galindo-Garre, Hidalgo, Guilera, Pino, Rojo, \& Gomez-Benito, 2014; Guilera et al. 2015; Uluğ, Ertuğrul, Göğüş, \& Kabakçi, 2001). For example, Galindo-Garre, Hidalgo, Guilera, Pino, Rojo, and Gomez-Benito (2014) administered the 36-item WHODAS 2.0 among 352 people with schizophrenia. Cronbach alpha scores for the six domains were (with domain in brackets): .83 (understanding and communicating), 
.65 (mobility), .50 (self-care), .81 (getting along), .91 (life activities), .87 (participation). Similarly Guilera et al. (2015) administered the 36-item WHODAS 2.0 among 291 patients with bipolar disorder. Cronbach alpha scores for the six domains were (with domain in brackets): .88 (understanding and communicating), .84 (mobility), .73 (self-care), .85 (getting along), .92 (life activities), .90 (participation). Previous studies have tested the concurrent validity of the WHODAS 2.0 against cognitive impairment measures and have generally found moderate to strong correlations (see the review by Federici, Bracalenti, Meloni, and Luciano [2017] for details about the studies where the concurrent validity was tested). For the current study, the Cronbach alpha scores of the six WHODAS 2.0 domains were (with domain in brackets): .816 (understanding and communicating), .531 (mobility), .179 (self-care), .623 (getting along), .943 (life activities), .876 (participation). The internal consistency for all 36 items of the WHODAS 2.0 was .917 .

\section{Data Analysis}

All statistical analysis were conducted using SPSS v22. Initially, descriptive statistics for the background information, the KICA-Cog (LoGiudice et al., 2006), WHODAS 2.0 (WHO, 2017), and the cognitive impairment diagnoses were tabulated. After, to establish the strength and direction of the relationship between being screened as potentially having dementia or global cognitive impairment (according to the KICA-Cog) and difficulties with activities of daily living (according to the WHODAS 2.0), a test for correlation (using Pearson's correlation coefficient) was conducted. Additionally, a difference between groups t-test was undertaken to establish if there were differences across activities of daily living domains for people who were screened as potentially having dementia or global cognitive impairment (according to the KICA-Cog).

\section{Findings}

\section{Cognitive Impairment}


Fifty one participants completed the KICA-Cog (LoGiudice et al., 2006) in entirety and across sample the mean score was $34.12(\mathrm{SD}=5.66)$. Descriptive statistics for the KICA-Cog domains have been included in Table 2 below. The lowest scale value was 17 and the highest value 39 . Of the fifty one participants who completed the KICA-Cog (LoGiudice et al., 2006), 35.3\% ( $\mathrm{n}=18)$ of participants scored below 33, indicative of screening positive for dementia or global cognitive impairment. In terms of clinical diagnosis, sixty participants, $70 \%(n=42)$ were identified as having a cognitive impairment. The first 4 clients seen were transferred to hospital via ambulance. Most required GP assessment by a service which attended the shelter on a weekly basis.

[Insert Table 2 Here]

\section{Difficulties in Activities of Daily Living}

Descriptive statistics for the six domains underpinning the WHODAS-36 (WHO, 2017) are included in Table 2. Each domain is scored individually out of 1.00 , where 0 indicates no disability and 1.00 indicates full disability. The domains identified as the most difficult by participants were (i) participation in society, and (ii) getting along with people. The least difficult domains were (i) selfcare and (ii) getting around. Accordingly, the least amount of participants indicated having no difficulty (i) participating in society and (ii) getting along with people, while the highest amount of participants had no difficulty (i) getting around, and with (ii) self-care. However as self-care produced a low internal consistency (individual items were not correlating well with each other), it is important that the results relating to self-care are treated with caution.

[Insert Table 3 Here]

\section{Impact of cognitive impairment on activities of daily living}

Correlation coefficients between the WHODAS 2.0 domains and those who have screened as having dementia and/or a global cognitive impairment according to the KICA-Cog have been included in Table 4. Findings conclude that there is a statistically significant correlation between being screened 
for dementia or global cognitive impairment according to the KICA-Cog and having greater difficulty with the WHODAS 2.0 domains Understanding or Communicating, Self-Care, and Life Activities. Additionally, being screened for dementia or global cognitive impairment according to the KICA-Cog was also correlated with having greater difficulty across the WHODAS 2.0 domains Participation in Society and Getting Along with People. For these domains, the correlations were not statistically significant yet trended towards significance.

[Insert Table 4 here]

Table 5 details where significant differences existed between those who had been screened for dementia and/or global cognitive impairment according to the KICA-Cog and those who did not. Significant differences between groups did not exist in terms of Aboriginal and/or Torres Strait Islander status, age and gender. Regarding WHODAS 2.0 domains, significant differences between groups existed for the domains Understanding or Communicating, Self Care, and Life Activities. Furthermore, those with an impairment indicated higher levels of difficulty across all domains.

[Insert Table 5 here]

\section{Discussion}

This is the first study to ascertain the point prevalence of cognitive impairment among a homeless cohort of individuals comprised mostly of Aboriginal and/or Torres Strait Islander people. Across the group approximately $35 \%$ of participants may have dementia or a global cognitive impairment based on the KICA-Cog while $70 \%$ had a clinically significant cognitive impairment which might be dementia, frontal lobe impairment and/or memory impairment. The discrepancy between the levels of impairment based on clinical diagnosis and KICA-cog screening is likely due to the participant sample having a high population of mentally ill people. The findings concluded that having an impairment according to the KICA-Cog was significantly correlated with having greater difficulty participating in society and getting along with other people. Finally, those who had a cognitive impairment according to the KICA-Cog indicated having a higher level of difficulty across all 
WHODAS 2.0 domains and the difference was significantly different for the domains: Understanding or Communicating, Self-Care, and Life Activities.

There are not studies to date which have involved a comparable cohort while also investigating the relationship between having a cognitive impairment and indicating difficulty across activities of daily living. While there are no studies across a comparable cohort to contextualise these findings, they do confirm findings from previous prevalence studies focusing on homeless populations more generally which identify that a considerable proportion of homeless people experience cognitive impairment (Burra et al., 2009; Stergiopoulos et al., 2015; Solliday-McRoy et al., 2004). For example, SollidayMcRoy, Campbell, Melchert, Young, and Cisler (2004) explored the level of cognitive impairment across a group of 90 male homeless adults. Within their study, cognitive impairment was found in $80 \%$ of the sample. Similarly, Stergiopoulos et al. (2015) explored the extent of cognitive impairment across a large cohort $(n=1500)$ of homeless adults. Findings concluded that over $70 \%$ had cognitive impairment.

People experiencing homelessness with a cognitive impairment are typically receiving inadequate support and treatment for their underlying conditions (Solliday-McRoy et al., 2004; Roy et al., 2015; Thurston et al., 2013). In terms of difficulty, across the sample, 'participation in society' and 'getting along with other people' were identified as the most difficult domains for participants, while 'getting around' and 'self-care' were identified as the least difficult. The ranking of these domains for homeless populations has also been confirmed by research in to date. For example, previous research has also identified that homeless populations with cognitive impairment have high levels of difficulty around social functioning (Herrman, Evert, Harvey, Gureje, Pinzone, \& Gordon, 2004; Van der Plas, Hoek, van Hoeken, Valencia, \& van Hemert, 2012). Van der Plas, Hoek, van Hoeken, Valencia, and van Hemert (2012) investigated the perceptions of quality of life and activities of daily living difficulty across a homeless cohort $(\mathrm{n}=50)$ with schizophrenia. The WHODAS 2.0 was used to investigate difficulties in activities of daily living and comparable to findings from this study, 'participation in society' was identified as the most difficult domain for the group. Similarly, 'getting along with other people' was identified as the third most difficult domain, which is close to findings 
from this study, which identified this domain as the second most difficult for participants. Also similar to the current study, for homeless participants within Van der Plas et al. (2012) 'getting around' and 'self-care' were identified as the least difficult domains for participants. Taken together, the findings suggest that homeless populations have the most difficulty participating in society and building social connections, and less difficulty getting around and self-care. These findings have implications for homeless service development and provision.

Issues pertaining to adequate support and treatment for their underlying conditions are of particular concern for Indigenous people, as culturally appropriate programs informed by Indigenous perspectives are not in place (Roy et al., 2015; Thurston et al., 2013). Across the developed world, a majority of homelessness solutions focus on housing (National Alliance to End Homelessness [NAEH], 2016; Raising the Roof [RTR], 2016), while not addressing underlying issues which may contribute to homelessness. Thus, the findings from this study demonstrate the importance of homeless support services developing supports specific to cognitive impairment. Such supports should address how to best support the activities of daily living of people who experience homelessness and have a cognitive impairment. In particular such supports should target the WHODAS 2.0 domains: understanding or communicating, self-care, and life activities. Furthermore, while a considerable proportion of participants were screened as having a cognitive impairment according to the KICA-Cog, $65 \%$ of participants were screened as not having an impairment. As such, support services should dedicate time and effort to understand the health assets which ensure the maintenance of cognitive health for people experiencing homelessness. Additionally, support services should provide programs which (i) encourage the maintenance of these health assets among those experiencing homelessness but not screened as having a cognitive impairment, and (ii) are generated among those experiencing homelessness who have been screened as having a cognitive impairment.

It is important that counselling and support programs offered to Aboriginal and/or Torres Strait Islander people are culturally sound (Vicary \& Bishop, 2005; Nelson et al., 2014). Where Australian homeless populations include a high proportion of Aboriginal and/or Torres Strait Islander people, support programs would benefit by taking guidance from the resource Working together: Aboriginal 
and Torres Strait Islander Mental Health and Wellbeing Principles and Practice (hereafter Working Together) (Purdie, Dudgeon, \& Walker, 2010). Working Together was developed as a tool to support health equity between Aboriginal and/or Torres Strait Islander and non-Aboriginal and/or Torres Strait Islander populations in Australia, particularly around mental health. Specifically, it was developed to '....educate and assist health professionals to work with Aboriginal and Torres Strait Islander people experiencing social and emotional wellbeing issues and mental health conditions...' (p.xxvi). The fourth section of Working Together includes five chapters which provide examples of models of practice for services and programs that aim to provide mental health support to Aboriginal and/or Torres Strait Islander people. For example, Chapter 17 titled Ngarlu: A Cultural and Spiritual Strengthening Model, describes a model focused on building the spirit, aimed towards persons who are recovering from a serious psychiatric illness. Thus, culturally appropriate programs like Ngarlu, built on principles of Aboriginal and/or Torres Strait Islander health and wellbeing have the potential to provide favourable support for homeless Aboriginal and/or Torres Strait Islander people within Australia.

This study has limitations that are important to consider when interpreting the findings. This was the first study - to the knowledge of the authors - to explore the prevalence of cognitive impairment across a homeless cohort including a majority of Aboriginal and/or Torres Strait Islander people. The cohort was attending a crisis shelter in Northern Queensland and consequently findings can only be generalizable to comparable groups within Australia. This study included 60 participants from a very hard to reach group. While the findings provide insight into the cognitive health of the specified group, it is important that further research explore the cognitive health outcomes across a larger cohort. It is important to acknowledge that the cognitive health of the specified group may have been impacted by a diverse set of factors including but not limited to head injury (a condition over represented among Indigenous people [see Author's Own, 2017c]) and/or drug and alcohol abuse and as such these factors must be considered in further research. Furthermore, while the research involved the guidance of Cultural Advisor, there is the potential that language and comprehension limitations may have impacted participant scores. Finally, all interview responses were self-reported by 
participants. While it is expected that participants answered accurately, there is the potential that their responses may have been influenced by different understandings of cognitive impairment, fear of stigma associated with impairment, mistrust and past experiences of racism and discrimination in services (Ypinazar, Margolis, Haswell-Elkins, \& Tsey, 2007).

This study included the KICA-Cog, and a psychiatrist diagnosis to explore the extent of cognitive impairment across the cohort, and the WHODAS 2.0 to ascertain individual difficulties around activities of daily living. The KICA-Cog has been identified as a tool to screen for cognitive impairment, particularly dementia across Aboriginal and/or Torres Strait Islander populations within the Kimberly, Western Australia and the Northern Territory (LoGiudice et al., 2011; Smith et al., 2009). The tool has been identified as an accurate tool to screen for dementia while may or may not be the best tool for other forms of cognitive impairment. Additionally, while the WHODAS 2.0 has been used to assess difficulties in activities of daily living across a variety of populations (see Federici, Bracalenti, Meloni \& Luciano, 2017), - to the knowledge of the authors - this was the first time it was used among a cohort of homeless people in Australia with a high proportion of Aboriginal and/or Torres Strait Islander people. Furthermore, there are no norms, or interpretation guidelines for the WHODAS 2.0 across homeless populations, and this is something which has previously been advocated for (see Konecky, Meyer, Marx, Kimbrel, and Morissette, 2014). The findings from this study suggest that an amended WHODAS 2.0 may be required for future assessments and/or studies which involve homeless cohorts with a majority of Aboriginal and/or Torres Strait Islander people. Particularly, the low internal consistency of the WHODAS 2.0 domain self-care indicates that the four included items are not well correlated, and thus may not be measuring the same construct. The only other study to date - to the knowledge of the authors - which has utilised the WHODAS 2.0 amongst a cohort experiencing homelessness is the previously referenced study by Van der Plas et al. (2012). Van der Plas et al. (2012) involved a cohort of 50 and did not report the internal consistency for the WHODAS 2.0 domain self-care. Consequently, a study involving a larger sample would be required to confirm whether or not an amended version of the WHODAS 2.0 is required. Finally, the validity of this tool among the specified cohort has yet to be established and it worthy of further investigation. 
Despite the stated limitations, this study being the first of its kind provides a strong evidence base towards an understanding of the level of cognitive impairment faced by homeless populations with a majority of Aboriginal and/or Torres Strait Islander people.

\section{Conclusion}

A large percentage of homeless populations may be experiencing cognitive impairment. The cognitive impairment experienced may be impacting homeless populations' ability to participate in society and develop social connections which may in turn negatively impact their ability to make choices about how they want to live. The impact of cognitive impairment may be increased by a lack of adequate, evidence based health and social support services which understand the nature of cognitive impairment within the group and appropriate service responses. This problem is further exacerbated in homeless populations which include a high proportion of Aboriginal and/or Torres Strait Islander people where services are not culturally safe and appropriate. Consequently, it is important that homeless policy and service development and reform is informed by evidence regarding the complex disability needs of homeless people in general; and, built on Aboriginal and/or Torres Strait Islander principles in order to correctly meet their health requirements.

\section{References}

Author's Own (2017a)

Author's Own (2017b)

Author's Own (2017c)

American Psychiatric Association (2013) Diagnostic and statistical manual of mental disorders (DSM-5®). American Psychiatric Pub.

Ardilly, P., \& Le Blanc, D. (2001). Sampling and weighting a survey of homeless persons: a French example. Survey methodology, 27(1), 109-118. 
Australia Buerea of Statistics (2015) Cairns Regional Statistics. Available at:

http://stat.abs.gov.au/itt/r.jsp?RegionSummary\&region=32080\&dataset=ABS REGIONAL

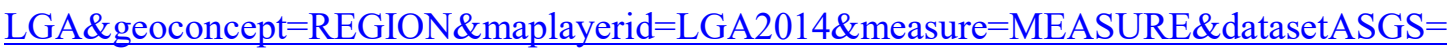
ABS_REGIONAL_ASGS\&datasetLGA=ABS_REGIONAL_LGA\&regionLGA=REGION\&r egionASGS=REGION (accessed 11 July 2017).

Avery, S. (2016) 'Living our Ways': A community-driven research program to understand the intersection of rights for Indigenous people with disability. The Lowitja Institute International Indigenous Health and Wellbeing Conference 2016. Melborune, Australia.

Biddle, N., Yap, M., and Gray, M. (2013) CAEPR Indigenous Population Project 2011 Census Papers. Canberra: Centre for Aboriginal Economic Policy Research, ANU.

Burra, T. A., Stergiopoulos, V., \& Rourke, S. B. (2009). A systematic review of cognitive deficits in homeless adults: implications for service delivery. The Canadian Journal of Psychiatry, 54(2), 123-133. https://doi.org/10.1177/070674370905400210

Cairns Regional Council (2017) Economic Profile. Available at: http://economy.id.com.au/cairns/employment-by-industry (accessed 11 July 2017).

Caspi, A., Houts, R. M., Belsky, D. W., Harrington, H., Hogan, S., Ramrakha, S., ... \& Moffitt, T. E. (2016). Childhood forecasting of a small segment of the population with large economic burden. Nature Human Behaviour, 1, 0005. https://doi.org/10.1038/s41562-016-0005

Caton, C. L., Wilkins, C., \& Anderson, J. (2007, September). People who experience long-term homelessness: Characteristics and interventions. In Toward Understanding Homelessness: 
The 2007 National Symposium on Homelessness Research. Washington, DC: US Department of Health and Human Services and Department of Housing and Urban Development.

Cullen J, Townsend C, White P, \& O'Brien, G. (2014) Innovative Approaches to Facilitate the Successful Implementation of the NDIS for Aboriginal and Torres Strait Islander People with Complex Disabilities. Australian \& New Zealand Journal of Psychiatry 48, 15-16.

Dudley, M. (2013) Exploring the Experiences of Maori Who Have Undergone Neuropsychological Assessment. Archives of Clinical Neuropsychology 28, 551-551.

Dudley, M., Wilson, D., \& Barker-Collo, S. (2014). Cultural invisibility: Māori people with traumatic brain injury and their experiences of neuropsychological assessments. New Zealand Journal of Psychology, 43(3), 14-21.

Fazel, S., Khosla, V., Doll, H., \& Geddes, J. (2008). The prevalence of mental disorders among the homeless in western countries: systematic review and meta-regression analysis. PLoS medicine, 5(12), e225. https://doi.org/10.1371/journal.pmed.0050225

Federici, S., Bracalenti, M., Meloni, F., \& Luciano, J. V. (2017). World Health Organization disability assessment schedule 2.0: An international systematic review. Disability and rehabilitation, 39(23), 2347-2380. https://doi.org/10.1080/09638288.2016.1223177

Fforde, C., Bamblett, L., Lovett, R., Gorringe, S., \& Fogarty, B. (2013). Discourse, deficit and identity: Aboriginality, the race paradigm and the language of representation in contemporary Australia. Media International Australia, 149(1), 162-173. 
Galindo-Garre, F., Hidalgo, M. D., Guilera, G., Pino, O., Rojo, J. E., \& Gómez-Benito, J. (2015). Modeling the World Health Organization Disability Assessment Schedule II using nonparametric item response models. International journal of methods in psychiatric research, 24(1), 1-10.

Glasson, E. J., Sullivan, S. G., Hussain, R., \& Bittles, A. H. (2005). An assessment of intellectual disability among Aboriginal Australians. Journal of Intellectual Disability Research, 49(8), 626-634. https://doi.org/10.1111/j.1365-2788.2005.00722.x

Guilera, G., Gómez-Benito, J., Pino, Ó., Rojo, E., Vieta, E., Cuesta, M. J., ... \& Martínez-Arán, A. (2015). Disability in bipolar I disorder: the 36-item world health organization disability assessment schedule 2.0. Journal of affective disorders, 174, 353-360.

Herrman, H., Evert, H., Harvey, C., Gureje, O., Pinzone, T., \& Gordon, I. (2004). Disability and service use among homeless people living with psychotic disorders. Australian and New Zealand Journal of Psychiatry, 38(11-12), 965-974. https://doi.org/10.1080/j.1440$\underline{1614.2004 .01488 . x}$

Hunter E (1993) Aboriginal health and history: Power and prejudice in remote Australia. Victoria, Australia: Cambridge University Press.

Hux, K., Schneider, T., \& Bennett, K. (2009). Screening for traumatic brain injury. Brain Injury, 23(1), 8-14. https://doi.org/10.1080/02699050802590353

Kalton, G. (2009). Methods for oversampling rare subpopulations in social surveys. Survey methodology, 35(2), 125-141. 
Konecky, B., Meyer, E. C., Marx, B. P., Kimbrel, N. A., \& Morissette, S. B. (2014). Using the WHODAS 2.0 to assess functional disability associated with DSM-5 mental disorders. American Journal of Psychiatry, 171(8), 818-820.

LoGiudice, D., Smith, K., Thomas, J., Lautenschlager, N. T., Almeida, O. P., Atkinson, D., \& Flicker, L. (2006). Kimberley Indigenous Cognitive Assessment tool (KICA): development of a cognitive assessment tool for older indigenous Australians. International Psychogeriatrics, 18(2), 269-280. https://doi.org/10.1017/s1041610205002681

LoGiudice, D., Strivens, E., Smith, K., Stevenson, M., Atkinson, D., Dwyer, A., ... \& Flicker, L. (2011). The KICA Screen: the psychometric properties of a shortened version of the KICA (Kimberley Indigenous Cognitive Assessment). Australasian journal on ageing, 30(4), 215219. https://doi.org/10.1111/j.1741-6612.2010.00486.x

National Alliance to End Homelessness (2016) Solutions. Available at: http://www.endhomelessness.org/pages/solutions (Accessed 13 July 2017)

Nelson, J., Ryan, K., Rotumah, D., Bennett-Levy, J., Budden, W., Stirling, J., ... \& Beale, D. (2014). Aboriginal practitioners offer culturally safe and responsive CBT: Response to commentaries. Australian Psychologist, 49(1), 22-27. https://doi.org/10.1111/ap.12041

O'Brien, G., Townsend-White, C., Cullen, J., White, P., \& Webster, A. (2014). Neurocognitive Disability Amongst Homeless Aboriginal and Torres Strait Islander Peoples: Preliminary Findings. Australian and New Zealand Journal of Psychiatry 48. 102-103. 
Purdie, N., Dudgeon, P., \& Walker, R. (2010) Working together: Aboriginal and Torres Strait Islander mental health and wellbeing principles and practice.

Roy, A., Noormohamed, R., Henderson, R. I., \& Thurston, W. E. (2015). Promising healing practices for interventions addressing intergenerational trauma among Aboriginal youth: A scoping review. First Peoples Child \& Family Review, 10(2), 62-81.

Raising the Roof (2016) Long-Term Solutions for Homelessness. Available at: http://www.raisingtheroof.org/about-homelessness/long-term-solutions-for-homelessness/ (Accessed 13 July 2017)

Madden, R. H., Glozier, N., Fortune, N., Dyson, M., Gilroy, J., Bundy, A., ... \& Madden, R. (2015). In search of an integrative measure of functioning. International journal of environmental research and public health, 12(6), 5815-5832. https://doi.org/10.3390/ijerph120605815

Queensland Council of Social Service (2016) Enabling Local Communities: Homelessness in Cairns. Report, Queensland Council of Social Service, March.

Queensland Council of Social Service (2011) QCOSS Regional Homelessness Profile Far North Statistical Division. Report, Queensland Council of Social Service, March.

Smith, K., Flicker, L., Dwyer, A., Marsh, G., Mahajani, S., Almeida, O., ... \& LoGiudice, D. (2009). Assessing cognitive impairment in indigenous Australians: re-evaluation of the Kimberley indigenous cognitive assessment in western Australia and the Northern Territory. Australian Psychologist, 44(1), 54-61. https://doi.org/10.1080/00050060802563463 
Solliday-McRoy, C., Campbell, T. C., Melchert, T. P., Young, T. J., \& Cisler, R. A. (2004).

Neuropsychological functioning of homeless men. The Journal of nervous and mental disease, 192(7), 471-478. https://doi.org/10.1097/01.nmd.0000131962.30547.26

Spence, S., Stevens, R., \& Parks, R. (2004). Cognitive dysfunction in homeless adults: a systematic review. Journal of the Royal Society of Medicine, 97(8), 375-379. https://doi.org/10.1258/jrsm.97.8.375

Stergiopoulos, V., Cusi, A., Bekele, T., Skosireva, A., Latimer, E., Schütz, C., ... \& Rourke, S. B. (2015). Neurocognitive impairment in a large sample of homeless adults with mental illness. Acta Psychiatrica Scandinavica, 131(4), 256-268. https://doi.org/10.1111/acps.12391

Thurston, W. E., Oelke, N. D., \& Turner, D. (2013). Methodological challenges in studying urban Aboriginal homelessness. International Journal of Multiple Research Approaches, 7(2), 250259. https://doi.org/10.5172/mra.2013.3502

Tourangeau, R., Edwards, B. and Johnson, T.P. eds., (2014) Hard-to-survey populations. United Kingdom: Cambridge University Press.

Uluğ, B., Ertuğrul, A., Göğüş, A., \& Kabakçi, E. (2001). Yeti yitimi değerlendirme çizelgesinin (WHO-DAS-II) şizofreni hastalarında geçerlilik ve güvenilirliği. Turk Psikiyatri Derg, 12, $121-30$.

Van der Plas, A. G. M., Hoek, H. W., van Hoeken, D., Valencia, E., \& van Hemert, A. M. (2012). Perceptions of quality of life and disability in homeless persons with schizophrenia and persons with schizophrenia living in non-institutional housing. International Journal of Social Psychiatry, 58(6), 629-634. https://doi.org/10.1177/0020764011419056 
Vicary, D., \& Bishop, B. (2005). Western psychotherapeutic practice: Engaging Aboriginal people in culturally appropriate and respectful ways. Australian Psychologist, 40(1), 8-19. https://doi.org/10.1080/00050060512331317210

Whittaker, E., Swift, W., Roxburgh, A., Dietze, P., Cogger, S., Bruno, R., ... \& Burns, L. (2015). Multiply disadvantaged: Health and service utilisation factors faced by homeless injecting drug consumers in Australia. Drug and alcohol review, 34(4), 379-387. https://doi.org/10.1111/dar.12257

World Health Organisation (2017) WHO Disability Assessment Schedule 2.0 Available at: http://www.who.int/classifications/icf/whodasii/en/ (Accessed 13 July 2017)

World Health Organization. (1993). The ICD-10 classification of mental and behavioural disorders: diagnostic criteria for research (Vol. 2). World Health Organization.

Worthington, C. A., \& MacLaurin, B. J. (2009). Level of street involvement and health and health services use of Calgary street youth. Canadian Journal of Public Health/Revue Canadienne de Sante'e Publique, 384-388.

Ypinazar, V. A., Margolis, S. A., Haswell-Elkins, M., \& Tsey, K. (2007). Indigenous Australians' understandings regarding mental health and disorders. Australian \& New Zealand Journal of Psychiatry, 41(6), 467-478. https://doi.org/10.1080/00048670701332953 
Table 1: Participant demographics

\begin{tabular}{|c|c|c|c|c|c|}
\hline \multirow[b]{2}{*}{ Characteristics } & \multicolumn{2}{|c|}{ Sample } & \multicolumn{2}{|c|}{ Service Users } & \multirow[t]{2}{*}{ Significance } \\
\hline & $\bar{n}$ & $\%$ & $\bar{n}$ & $\%$ & \\
\hline \multicolumn{6}{|l|}{ Ethnicity } \\
\hline Aboriginal and/or Torres Strait & 45 & 75 & 66 & 48.5 & $* * *(\mathrm{p}=.001)$ \\
\hline Neither Aboriginal nor Torres Strait & 15 & 25 & 67 & 49.3 & \\
\hline Missing & 0 & 0 & 3 & 2.2 & \\
\hline \multicolumn{6}{|l|}{ Gender } \\
\hline Male & 40 & 66.7 & 103 & 75.7 & $\mathrm{~ns}$ \\
\hline Female & 20 & 33.3 & 33 & 24.3 & \\
\hline \multicolumn{6}{|l|}{ Age } \\
\hline $15-20$ & 3 & 5 & 8 & 5.8 & \\
\hline $20-29$ & 8 & 13.3 & 20 & 14.8 & \\
\hline $30-39$ & 14 & 23.3 & 31 & 12.8 & \\
\hline $40-49$ & 14 & 23.3 & 45 & 33.1 & \\
\hline $50-59$ & 7 & 11.7 & 21 & 15.4 & \\
\hline $60+$ & 5 & 8.3 & 10 & 7.4 & \\
\hline Unknown & 9 & 15 & 1 & 0.7 & \\
\hline \multicolumn{6}{|l|}{ Where have you been living during the } \\
\hline Homeless/no fixed address & 48 & & & & \\
\hline Crisis shelter or rooming house & 17 & & & & \\
\hline
\end{tabular}




\begin{tabular}{|c|c|c|}
\hline Hospital & 1 & \\
\hline Hotel & 1 & \\
\hline Rented room - public & 2 & \\
\hline Rented room - private & 5 & \\
\hline Family home & 1 & \\
\hline Other & 7 & \\
\hline Living across more than one location & 20 & \\
\hline \multicolumn{3}{|l|}{ Where have you lived for more than a } \\
\hline Homeless/no fixed address & 58 & \\
\hline Crisis shelter or rooming house & 25 & \\
\hline Hostel & 1 & \\
\hline Hospital & 2 & \\
\hline Hotel & 1 & \\
\hline Rented home - public & 11 & \\
\hline Rented home - private & 17 & \\
\hline Family home & 9 & \\
\hline Other & 8 & \\
\hline Living across more than one location & 41 & \\
\hline \multicolumn{3}{|l|}{ Do you have a job at present? } \\
\hline No & 59 & 98.3 \\
\hline Yes - Part time & 1 & 1.7 \\
\hline \multicolumn{3}{|l|}{ At any time in the last 4 weeks have you } \\
\hline No & 40 & 66.7 \\
\hline Yes-Full time & 10 & 16.7 \\
\hline Yes - Part time & 2 & 3.3 \\
\hline Not in labour force & 8 & 13.3 \\
\hline \multicolumn{3}{|l|}{ Were you off work mainly because of a } \\
\hline Mainly physical health & 21 & 35 \\
\hline Mainly mental health & 35 & 58.3 \\
\hline Both & 4 & 6.7 \\
\hline \multicolumn{3}{|l|}{ Have you received any of the following } \\
\hline Disability support/invalid pension & 23 & 38.3 \\
\hline Newstart/job search/mature age & 35 & 58.3 \\
\hline Unemployed benefit & 1 & 1.7 \\
\hline Not known & 1 & 1.7 \\
\hline
\end{tabular}


Table 2: KICA-Cog descriptive statistics

\begin{tabular}{l|rrrrrr}
$\begin{array}{l}\text { KICA-Cog } \\
\text { Domain }\end{array}$ & N & Mean & $\begin{array}{c}\text { Std. } \\
\text { Deviation }\end{array}$ & Range & Min. & Max. \\
\hline Orientation & 58 & 2.6379 & .64068 & 2 & 1 & 3 \\
Recognition & 56 & 5.8393 & .59625 & 3 & 3 & 6 \\
Registration & 58 & 2.6724 & .82479 & 3 & 0 & 3 \\
Comprehension & 58 & 3.0000 & 0.00000 & 0 & 3 & 3 \\
Fluency & 56 & 2.1607 & .86921 & 3 & 0 & 3 \\
Recall & 57 & 2.6316 & .77070 & 3 & 0 & 3 \\
Visual Naming & 56 & 4.5000 & .85280 & 3 & 2 & 5 \\
Frontal Executive & 56 & .6964 & .46396 & 1 & 0 & 1 \\
Function & 56 & 3.8750 & 1.71689 & 5 & 0 & 5 \\
Free Recall & 57 & 4.1228 & 1.91861 & 5 & 0 & 5 \\
Cued Recall & 57 & 2.0000 & 0.00000 & 0 & 2 & 2 \\
Praxis & 51 & 34.12 & 5.663 & 22 & 17 & 39 \\
\hline Total KICA-Cog & & & & & & \\
Score & &
\end{tabular}


Table 3: World Health Organisation Disability Assessment Schedule 2.0 Complex Scoring

\begin{tabular}{|c|c|c|c|c|}
\hline WHODAS DOMAINS & $\mathbf{N}$ & Mean & SD & $\begin{array}{l}\text { Participants } \\
\text { with no } \\
\text { difficulty }\end{array}$ \\
\hline Participation in society & 52 & .2686 & .2353 & 7 \\
\hline Getting along with people & 51 & .1784 & .1563 & 11 \\
\hline Understanding and communicating & 55 & .1083 & .1324 & 23 \\
\hline Life activities & 49 & .0759 & .1596 & 33 \\
\hline Getting around & 54 & .0565 & .0855 & 34 \\
\hline Self-care & 55 & .0352 & .0599 & 36 \\
\hline
\end{tabular}


Table 4: Correlation coefficients between WHODAS 2.0 domains and KICA-Cog screening

\begin{tabular}{|c|c|c|c|c|c|c|c|}
\hline & & $\begin{array}{l}\text { Understanding } \\
\text { Communicating } \\
\end{array}$ & $\begin{array}{l}\text { Getting } \\
\text { Around }\end{array}$ & Self Care & $\begin{array}{l}\text { Getting } \\
\text { Along With } \\
\text { People }\end{array}$ & $\begin{array}{c}\text { Life } \\
\text { Activities }\end{array}$ & $\begin{array}{l}\text { Participation } \\
\text { In Society }\end{array}$ \\
\hline \multirow{3}{*}{$\begin{array}{l}\text { Screened for } \\
\text { Cognitive } \\
\text { Impairment (KICA- } \\
\text { Cog) }\end{array}$} & $\begin{array}{l}\text { Pearson } \\
\text { Correlation }\end{array}$ & $.392^{* *}$ & .073 & $.421^{* *}$ & .261 & $.494^{* *}$ & .239 \\
\hline & $\begin{array}{l}\text { Sig. (2- } \\
\text { tailed) }\end{array}$ & .005 & .621 & .003 & .080 & .001 & 109 \\
\hline & $\mathrm{N}$ & 50 & 48 & 49 & 46 & 44 & 46 \\
\hline
\end{tabular}

*. Correlation is significant at the 0.05 level (2-tailed).

**. Correlation is significant at the 0.01 level (2-tailed). 
Table 5: Between group differences

\begin{tabular}{|c|c|c|c|}
\hline & No Impairment & $\begin{array}{l}\text { Screened for } \\
\text { Impairment } \\
\end{array}$ & \\
\hline Characteristic/Domain & $\begin{array}{l}\text { Mean [or } \\
\text { Frequency] }\end{array}$ & $\begin{array}{c}\text { Mean [or } \\
\text { Frequency] }\end{array}$ & $\begin{array}{c}\text { Sig } \\
\text { Difference }\end{array}$ \\
\hline Indigenous & {$[23]$} & {$[15]$} & ns \\
\hline Male & [23] & [13] & ns \\
\hline Age & 40.04 & 42.86 & ns \\
\hline $\begin{array}{l}\text { Understanding or } \\
\text { Communicating }\end{array}$ & .0651 & .1667 & $* *$ \\
\hline Getting Around & .0484 & .0618 & ns \\
\hline Self Care & .0137 & .0625 & $* *$ \\
\hline $\begin{array}{l}\text { Getting Along with } \\
\text { Other People }\end{array}$ & .1448 & .2324 & ns \\
\hline \multirow{2}{*}{$\begin{array}{l}\text { Life Activities } \\
\text { Participation in Society }\end{array}$} & .0100 & .1230 & $* *$ \\
\hline & .2039 & .3154 & ns \\
\hline
\end{tabular}

* Difference is significant at the .05 level

** Difference is significant at the .01 level 
